\title{
Disziplin - zusammenarbeiten wie in einem Orchester
}

Ohne eine gemeinsame Arbeitshaltung läuft der Unterricht nicht - das Ideal ist ein Umgang miteinander wie in einem Orchester. Das Ziel ist ein tolles Konzert mit viel Applaus. Dann muss aber jeder sein Instrument richtig spielen, sonst entsteht kein harmonischer Musikgenuss. Und jeder muss auch die Noten der anderen Orchestermitglieder und den Dirigenten beachten.

Im Mathematikunterricht ist es nicht viel anders, Disziplin ist funktionale Disziplin, die man sinnvollerweise seinen Schülerinnen und Schülern vor allem auch erforderlichenfalls öfter erklärt. Zusammenarbeit in einer Klasse gelingt nur, wenn man andere respektiert, wenn man möglichst genau den anderen zuhört, wenn man stilvoll und konstruktiv kritisiert und weiterdenkt. Dies alles muss man jedoch lernen - übrigens mit unserer Assistenz.

Wenn dann jemand - was ja vorkommen soll - einer klaren Ansprache bedarf, so besteht die Kunst darin, es so zu machen, dass es wirkt, und dennoch erkennbar Sympathie im Spiel ist. 